\title{
Berberine induces apoptosis via the mitochondrial pathway in liver cancer cells
}

\author{
NOVIA K.Y. YIP and W.S.HO \\ School of Life Sciences, The Chinese University of Hong Kong, Shatin, Hong Kong SAR, P.R. China
}

Received January 23, 2013; Accepted April 4, 2013

DOI: $10.3892 /$ or.2013.2543

\begin{abstract}
Current chemotherapeutic strategies for liver cancer have limitations. Thus, the demand for complementary medicine is warranted. We evaluated the antitumor potential of berberine, a naturally bioactive phytochemical from Coptis chinensis Franch against Huh7 cancer cells and WRL68 liver cells. The antitumor activity of berberine was evaluated by flow cytometry. The caspase-dependent pathway was assessed using western blot analysis. Results showed that berberine induced the apoptosis of liver cancer cells through procaspase-9, and its effector caspases, procaspase-3 and procaspase-7. Flow cytometry revealed that berberine caused cell cycle arrest at the M/G1 phase. The results of reverse transcription-polymerase chain reaction showed that berberine increased the expression of Bax, which resulted in the activation of the caspase cascade. The present findings demonstrated that berberine induces the apoptosis of Huh7 cells via the mitochondrial pathway.
\end{abstract}

\section{Introduction}

Liver cancer is the fifth most common cancer and the seventh most frequently diagnosed cancer worldwide (1). Among primary liver cancers occurring worldwide, hepatocellular carcinoma (HCC) represents the major histological type, which accounts for 70-85\% of cases (2). Half of the liver cancer cases and deaths were estimated to occur in China for both men and women (1). The high HCC rate in China and in developing countries largely reflects the elevated prevalence of chronic hepatitis B virus (HBV) infection, with over $8 \%$ of the populations in these regions chronically infected with the virus (3). Hepatitis $\mathrm{C}$ virus ( $\mathrm{HCV}$ ) infection accounts for $33 \%$ of the total liver cancer cases in developing countries, and for $20 \%$ in developed countries. Interaction of aflatoxin B (AFB) exposure and chronic HBV infection is known to increase

Correspondence to: Professor W.S. Ho, School of Life Sciences, The Chinese University of Hong Kong, Shatin, Hong Kong SAR, P.R. China

E-mail:ws203ho@cuhk.edu.hk

Key words: berberine, apoptosis, Huh7, anti-proliferative, caspase cascade the risk of liver cancer (4). Alcohol-associated cirrhosis and possibly non-alcoholic fatty liver disease are believed to be related to obesity and are the leading causes of liver cancer (5). However, current chemotherapeutic strategies have serious limitations and yield undesirable side effects. Moreover, no vaccine is available for $\mathrm{HCV}$. Preventive strategies against $\mathrm{HCV}$ and complementary medicine are needed to reduce the number of cancer deaths.

Previous studies have reported the pharmacological properties of Coptis chinensis Franch formulation for the treatment of various liver disorders and its major constituent triterpenoids (6-8). One of the major constituent phytochemicals was demonstrated to exhibit marked anti-inflammatory and anti-proliferative effects on cancer cells. However, the details of its mechanisms are lacking.

In the present study, the Huh7 liver cancer cell line and the WRL68 normal liver cell line were used to study the antitumor activity of berberine from Coptis chinensis Franch, which is commonly used in combination with other herbs for the treatment of various diseases. Additionally, the mode of action of berberine in the Huh7 cell line was investigated.

\section{Materials and methods}

Chemicals and reagents. Berberine chloride was purchased from Sigma-Aldrich Inc. (China), and Dulbecco's phosphatebuffered saline (DPBS), fetal bovine serum (FBS), a penicillin/ streptomycin antibiotic solution (PS), Roswell Park Memorial Institute (RPMI)-1640 medium, and Trypsin-EDTA (1X) were purchased from Invitrogen Life Technologies (Carlsbad, CA, USA). Minimal essential medium (MEM) was purchased from ATCC (Manassas, VA, USA). 3-(4,5-Dimethylthiazol2-yl)-2,5-diphenyltetrazolium bromide (MTT) and sodium bicarbonate were obtained from Sigma Chemicals (St. Louis, MO, USA). Dimethyl sulfoxide (DMSO) was purchased from Fisher Scientific Inc. (Rockford, IL, USA). The Millex-GP filter $(0.22-\mu \mathrm{m})$ was purchased from Millipore (Billerica, MA, USA). Tissue culture flasks $\left(75-\mathrm{cm}^{2}\right)$ were ordered from Corning, USA. Ninety 6-well microplates were purchased from Iwaki. Culture dishes (100-mm) were purchased from Greiner Bio-One (Germany).

Cell treatment. WRL68 liver cells and Huh7 liver cancer cells were grown in RPMI-1640 with $10 \%$ FBS. Cells were suspended with fresh complete medium $(5 \mathrm{ml})$ and were 
centrifuged at $600 \mathrm{x}$ g for $3 \mathrm{~min}$. The cell pellets were washed with $1 \mathrm{ml}$ of DPBS before centrifugation at $600 \mathrm{x}$ g for $3 \mathrm{~min}$. Cells were transferred to a new $75-\mathrm{cm}^{2}$ culture flask with $12 \mathrm{ml}$ of complete medium. The flask was stored in a $37^{\circ} \mathrm{C}$ incubator supplied with $5 \%$ carbon dioxide before use.

MTT assay. Huh7 and WRL68 cells $\left(1 \times 10^{6}\right)$ were seeded onto a 96-well plate overnight prior to incubation with various concentrations of berberine for 24,48 and $72 \mathrm{~h}$, respectively. MTT solution $(20 \mu \mathrm{l})$ was added to each well, and the plate was maintained at $37^{\circ} \mathrm{C}$ with $5 \%$ carbon dioxide for $4 \mathrm{~h}$. After incubation, the plate was dried. DMSO $(200 \mu \mathrm{l})$ was added to dissolve the purple formazan formed in the assay prior to measurement of absorbance at $540 \mathrm{~nm}$. The $\mathrm{IC}_{50}$ value was determined.

Detection of apoptosis by fluorescein isothiocyanate (FITC) Annexin V and propidium iodide (PI) co-staining. Huh7 cells were treated according to the manufacturer's protocol. Cells were treated with different concentrations of berberine for 24, 48 and 72 h, respectively. Following berberine treatment, cells were harvested with trypsin and stained according to the BD Pharmingen $^{\mathrm{TM}}$ FITC Annexin V staining protocol. The stained cells were analyzed using a FACSCanto ${ }^{\mathrm{TM}}$ instrument. Data were analyzed with software FlowJo 7.6.1.

Gene expression in berberine-induced apoptotic cells. Total RNA was extracted using the RNeasy mini kit (Qiagen, Hilden, Germany) according to the manufacturer's protocol. First-strand cDNA was synthesized using $1 \mu \mathrm{g}$ of total RNA using the Transcriptor First Strand cDNA Synthesis kit (Roche Diagnostics). Anchored-oligo(dT)18 primer was used in the template-master mix. Experimental cocktail was prepared as recommended by RT2 Profiler ${ }^{\mathrm{TM}}$ polymerase chain reaction (PCR) array system pathway-focused gene expression profiling using real-time PCR protocol.

Western blot analysis of gene expression in berberinetreated cells. Huh7 cells $\left(1 \times 10^{6}\right)$ were seeded onto a $100-\mathrm{mm}$ culture dish overnight prior to incubation with berberine. Following the incubation of cells with berberine for $72 \mathrm{~h}$, cell lysates were extracted using whole cell lysis buffer. The protein concentration was determined by the DC protein assay (Bio-Rad). The protein was transferred onto a PVDF membrane (Pall Corp.). The blots were treated with blocking solution (5\%) for $1 \mathrm{~h}$, and were probed with a specific primary antibody with $5 \%$ non-fat milk powder in TBST at $4^{\circ} \mathrm{C}$ overnight. After washing with TBST, the blots were treated with the specific HRP-linked secondary antibody for $1 \mathrm{~h}$ and were washed thrice. Proteins were detected using Rodeo $^{\mathrm{TM}}$ ECL western blotting reagents (USB, Cleveland, OH, USA) according to the manufacturer's protocol.

Caspase cascade in berberine-treated cells. Cells were treated with different concentrations of berberine for $72 \mathrm{~h}$. Apo-ONE ${ }^{\circledR}$ Homogeneous Caspase-3/7 assay was performed according to the 'Promega Technical Bulletin-Apo-ONE ${ }^{\circledR}$ Homogeneous Caspase-3/7 assay instructions for use of products G7790, G7791 and G7792'. The plate was incubated and shaken at room temperature for $2 \mathrm{~h}$. The fluorescence of each

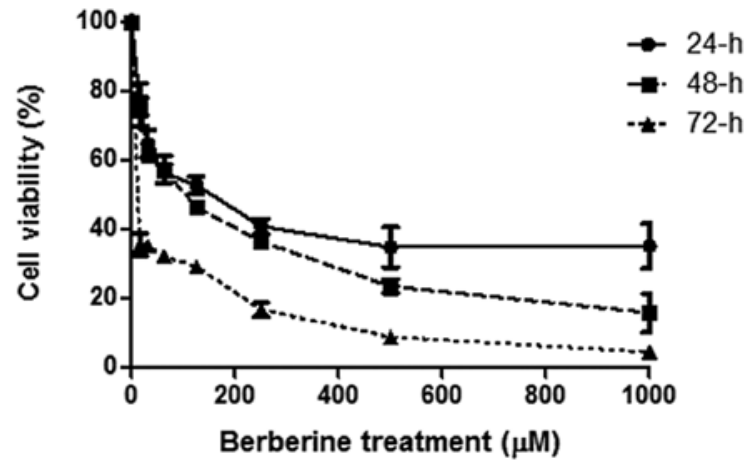

Figure 1. Cell viability of Huh7 cells following incubation with berberine for 24,48 and $72 \mathrm{~h}$. The data represent the means \pm SD of three individual experiments $(\mathrm{P}<0.01)$.

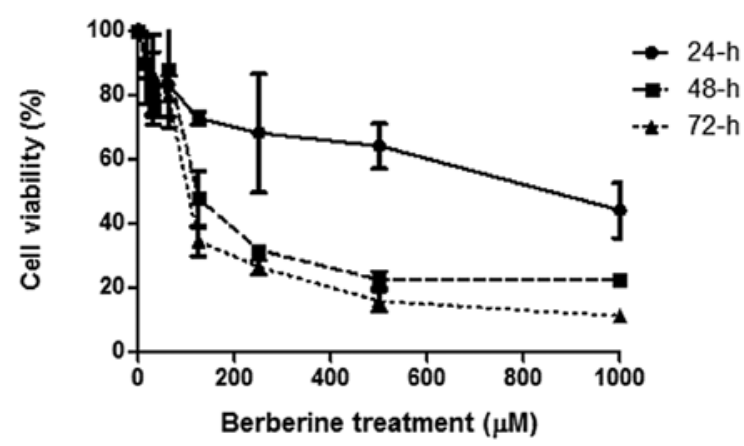

Figure 2. Cell viability of WRL68 cells following incubation with berberine for 24,48 and $72 \mathrm{~h}$. The data represent the means \pm SD of three individual experiments $(\mathrm{P}<0.01)$.

well was measured (excitation wavelength, $485 \mathrm{~nm}$; emission wavelength, $520 \mathrm{~nm}$ ).

Cell cycle analysis of Huh7 cells. Cells were harvested with trypsin after berberine treatment and washed with cold DPBS twice. Cells were collected by centrifugation and re-suspended in cold $70 \%(\mathrm{w} / \mathrm{v})$ ethanol at a concentration of $1 \times 10^{6}$ cells $/ \mathrm{ml}$ for $24 \mathrm{~h}$ before being washed by cold DPBS. Cells were re-suspended with $400 \mu 1$ of PI solution and transferred to a $5-\mathrm{ml}$ polystyrene round-bottom tube at $25^{\circ} \mathrm{C}$ in the dark for 15 min prior to analysis by BD FACSCanto ${ }^{\mathrm{TM}}$ flow cytometer.

Statistical analysis. FACSDiva ${ }^{\mathrm{TM}}$ software was used to operate the BD FACSCanto ${ }^{\mathrm{TM}}$ flow cytometer. Experimental data were captured and were analyzed by FlowJo 7.6.1. The percentage of cell populations in the G1, G2 and S phases of the cell cycle was recorded. The experiment was performed three times. The ratios of cells in the G0/G1, intra-S and $\mathrm{G} 2 / \mathrm{M}$ phases were expressed as means $\pm \mathrm{SD}$.

\section{Results}

Berberine induces apoptosis of hepatocellular cells. Effects of berberine on the viability of hepatocellular carcinoma (HCC) cells (Fig. 1) and normal liver cells (Fig. 2) were evaluated by the MTT assay. The $\mathrm{IC}_{50}$ for Huh7 was $10 \mu \mathrm{M}$ while the $\mathrm{IC}_{50}$ for WRL68 cells was $100 \mu \mathrm{M}$ berberine following a 
Table I. $\mathrm{IC}_{50}(\mu \mathrm{M})$ values for Huh7 and WRL68 liver cell lines after incubation with berberine for different time periods.

\begin{tabular}{lrrr}
\hline Time (h) & 24 & 48 & 72 \\
\hline Huh7 & 150 & 100 & 10 \\
WRL68 & 1000 & 120 & 100 \\
\hline
\end{tabular}
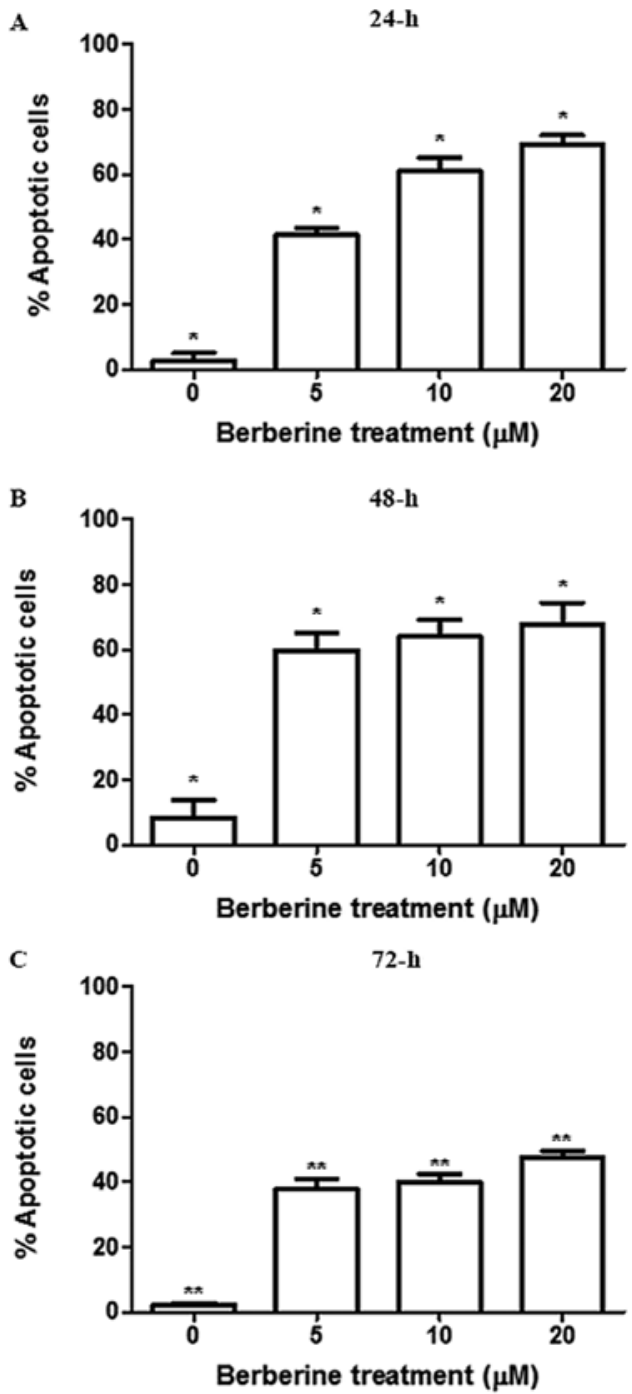

Figure 3. Berberine induces apoptosis. Percentage of apoptotic Huh7 cells after (A) $24 \mathrm{~h}$, (B) $48 \mathrm{~h}$ and (C) $72 \mathrm{~h}$ treatment with different concentrations of berberine. Data represent the means \pm SD from three independent experiments $\left({ }^{*} \mathrm{P}<0.05,{ }^{* * *} \mathrm{P}<0.01,{ }^{* * * *} \mathrm{P}<0.001\right)$.

72-h treatment. Table I summarizes the $\mathrm{IC}_{50}$ values of the two cell lines after berberine treatment. Apoptosis of HCC cell lines was detected by the BD Pharmingen ${ }^{\mathrm{TM}}$ FITC Annexin V Apoptosis Detection Kit I. The results demonstrated that berberine induced the cell death of Huh7 cells. The results showed that cell viability of Huh7 cells was reduced after 24,48 and $72 \mathrm{~h}$ of incubation with berberine (Fig. 3). The percentage of apoptotic cells increased with the increase in berberine concentration. The results showed that berberine induced the apoptosis of Huh7 cells.

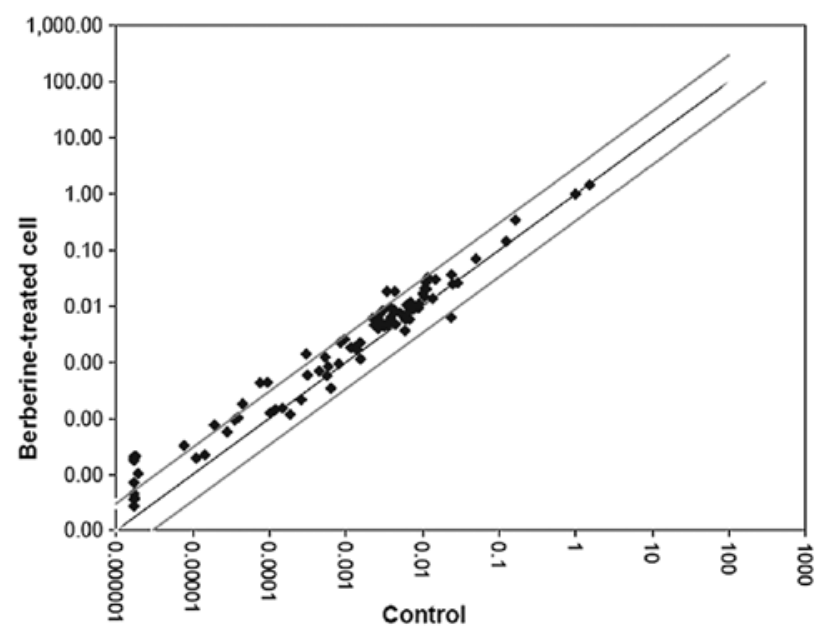

Figure 4. PCR array profile of upregulated and downregulated genes in Huh7 cells following $72 \mathrm{~h}$ treatment with berberine. The middle line indicates relative fold changes. The left and right lines indicate the fold-change in gene expression threshold, which was defined as 3 -fold.

Gene expression profile in the berberine-treated cells. Gene expression profile in the HCC cell line was assessed by PCR array and real-time PCR. PCR array was used to profile the gene expression in the Huh7 cells. Real-time PCR was used for the quantitative measurement of gene expression in the berberine-treated HCC cells.

PCR array was used as a preliminary screening procedure for genes that were significantly affected by berberine (Fig. 4). The relative gene expression levels in the cell samples were plotted against the control in a scatter plot using the program provided by the manufacturer. The middle line indicates relative fold changes. The left and right lines indicate the fold-change in gene expression threshold, which was defined as 3-fold. Outliers of the left line were found to be genes upregulated by at least 3-fold, which included BCL2, BCL2L1, CASP14, CD40, CIDEA, FASLG, GADD45A, HRK, LTA, TNFRSF10A, TNFRSF10B, CD27, TNFRSF9 and CD70. The outlier of the right line was BCLAF1, which was downregulated by at least 3 -fold. Bax, Bid, CIDEA, HRK and p21 were found to be upregulated by berberine in a dose-dependent manner, while AKT and Bcl-2 were found to be downregulated by berberine in a dose-dependent manner. The gene expression of survivin decreased with the increase in berberine concentration. The gene expression of $\mathrm{Bcl}-2$, CIDEA and HRK was validated by real-time PCR (Fig. 5). The real-time PCR results corroborated with the PCR array analysis in regards to the CIDEA gene.

Caspase cascade and the cell cycle distribution in the berberine-treated Huh7 cell line. The caspase cascade was evaluated by SDS-PAGE (Fig. 6) and western blot analysis (Fig. 7). The expression of Bcl-2 protein family members including Bcl-2 and Bid, and PARP and PCNA was altered following treatment with berberine (Fig. 8).

Cell cycle analysis showed that there was an increase in the G1 cell population with an increase in the concentration of berberine, suggesting that berberine caused G1 phase cell cycle arrest in the Huh7 cells. The cell cycle distribution was 


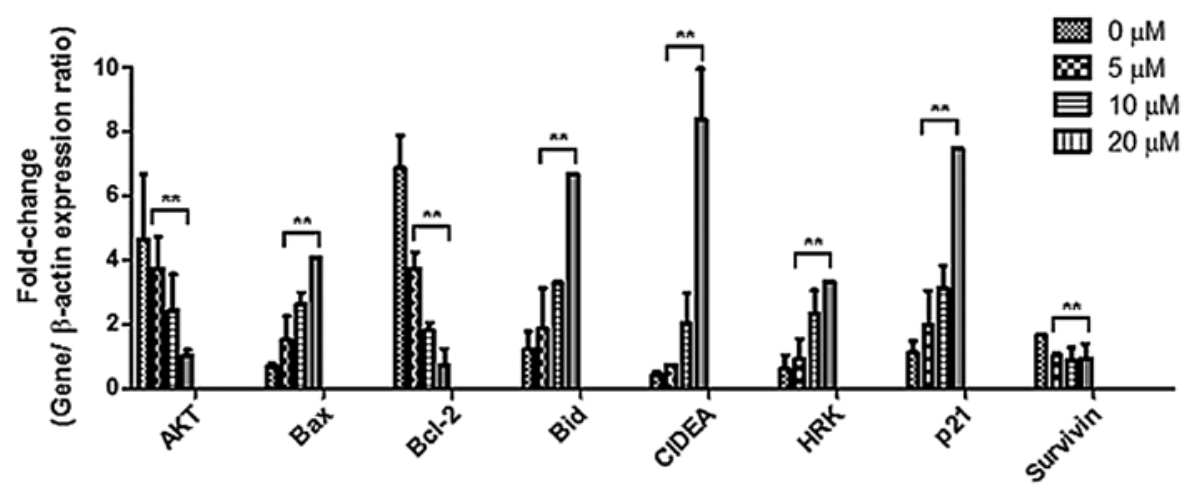

Figure 5. RT-PCR analysis indicates that berberine modulates gene expression in Huh7 cells. Total RNA from berberine-treated and untreated Huh7 cells was extracted after $72 \mathrm{~h}$ of incubation, and cDNA was synthesized from the total RNA. Real-time PCR was carried out according to the manufacturer's protocol. Bax, Bid, CIDEA, HRK and p21 genes were found to be upregulated while AKT and Bcl-2 were found to be downregulated by berberine in a dose-dependent manner. The gene expression of survivin decreased with the increase in berberine concentration. The data represent the means \pm SD of three individual experiments $\left({ }^{* *} \mathrm{P}<0.01\right)$.

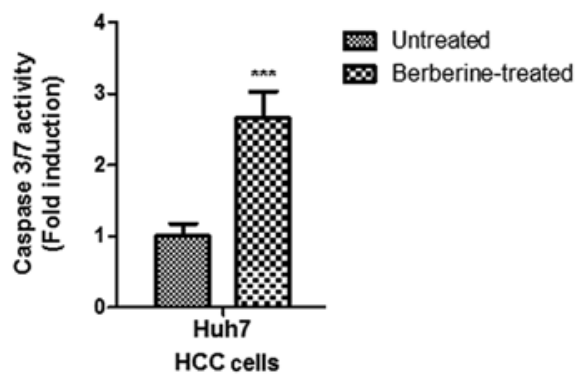

Figure 6. Caspase-3/7 activity in Huh7 cells following incubation with $30 \mu \mathrm{M}$ berberine for $72 \mathrm{~h}$. Caspase substrate Z-DEVD-R110 was added according to the assay kit protocol. The fluorescence was measured with the excitation wavelength at $495 \mathrm{~nm}$, and the emission wavelength at $595 \mathrm{~nm}$. The data represent the means $\pm \mathrm{SD}$ of three individual experiments $\left.{ }^{* * * *} \mathrm{P}<0.001\right)$.
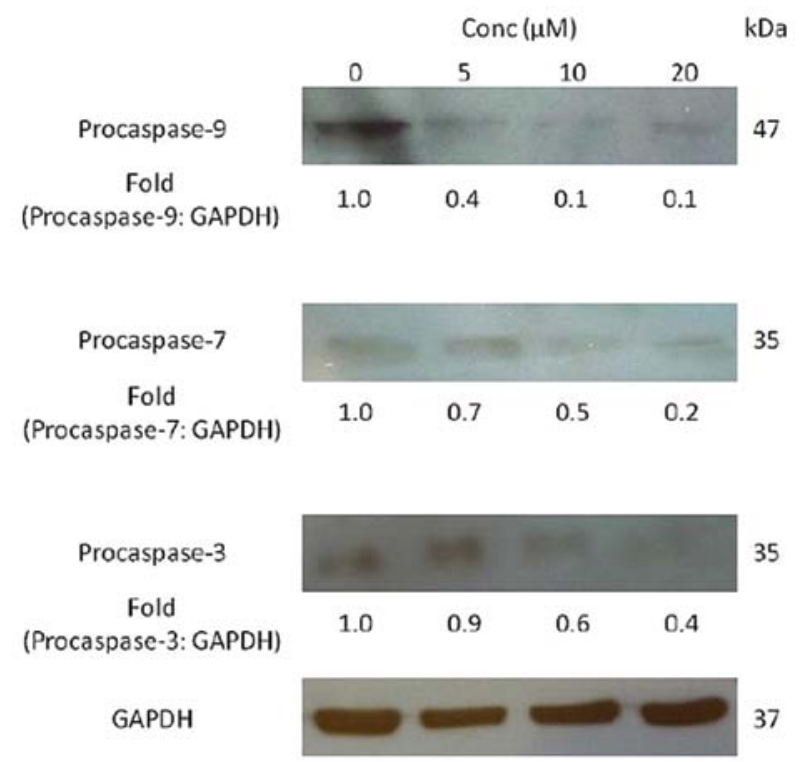

Figure 7. Western blot analysis of procaspase-9, procaspase-7 and procaspase-3 in the Huh7 cells after a 72-h incubation with berberine. The data represent the means $\pm \mathrm{SD}$ of three individual experiments.

investigated at three time points: 24,48 and $72 \mathrm{~h}$, respectively (Fig. 9). Fig. 9A and B shows that there was a slight

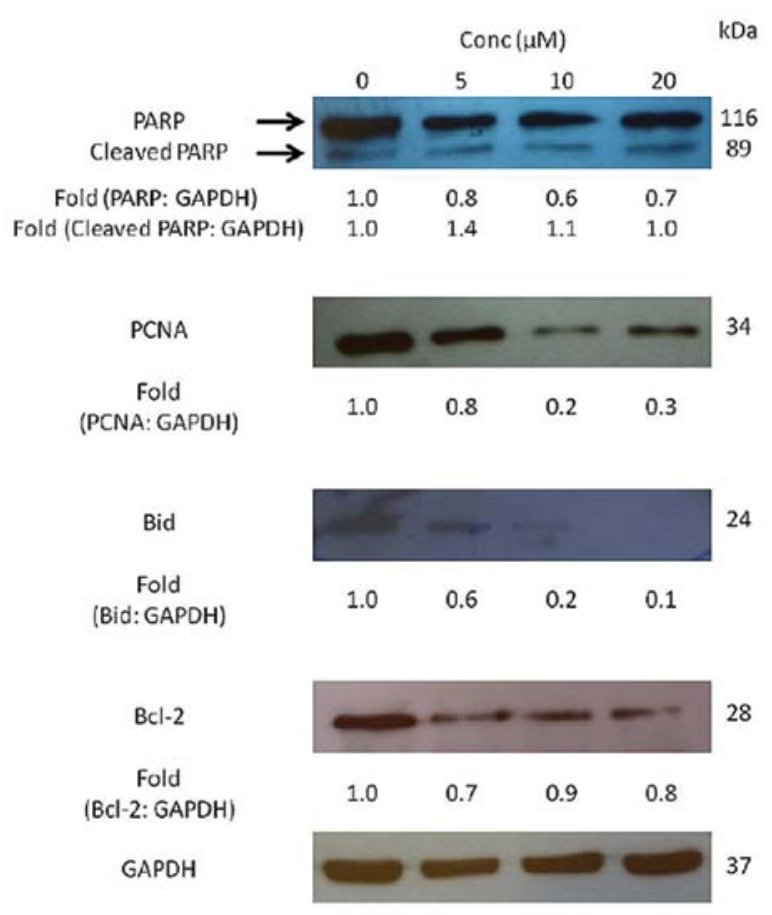

Figure 8. Western blot analysis of PARP, cleaved PARP, PCNA, Bid, and Bcl-2 in the Huh7 cells following a 72-h incubation with berberine. The results indicate that berberine caused cleavage of PARP, which is an important apoptotic marker. The expression of PCNA, Bid and Bcl-2 in the Huh7 cells was decreased with an increase in berberine concentration. The data represent the means $\pm \mathrm{SD}$ of three individual experiments.

increase in the percentage of cells in the G1 phase with an increase in berberine concentration. Fig. 9B-D reveals that the percentage of cells in the G1 phase following treatment with 5, 10 and $20 \mu \mathrm{M}$ increased by $10 \%$ compared with the percentage of cells in the control without berberine treatment. The distribution of the cell cycle is shown in Fig. 10.

\section{Discussion}

Berberine was found to reduce the cell viability of Huh7 cells in a dose-dependent manner. It exhibited a relatively reduced 

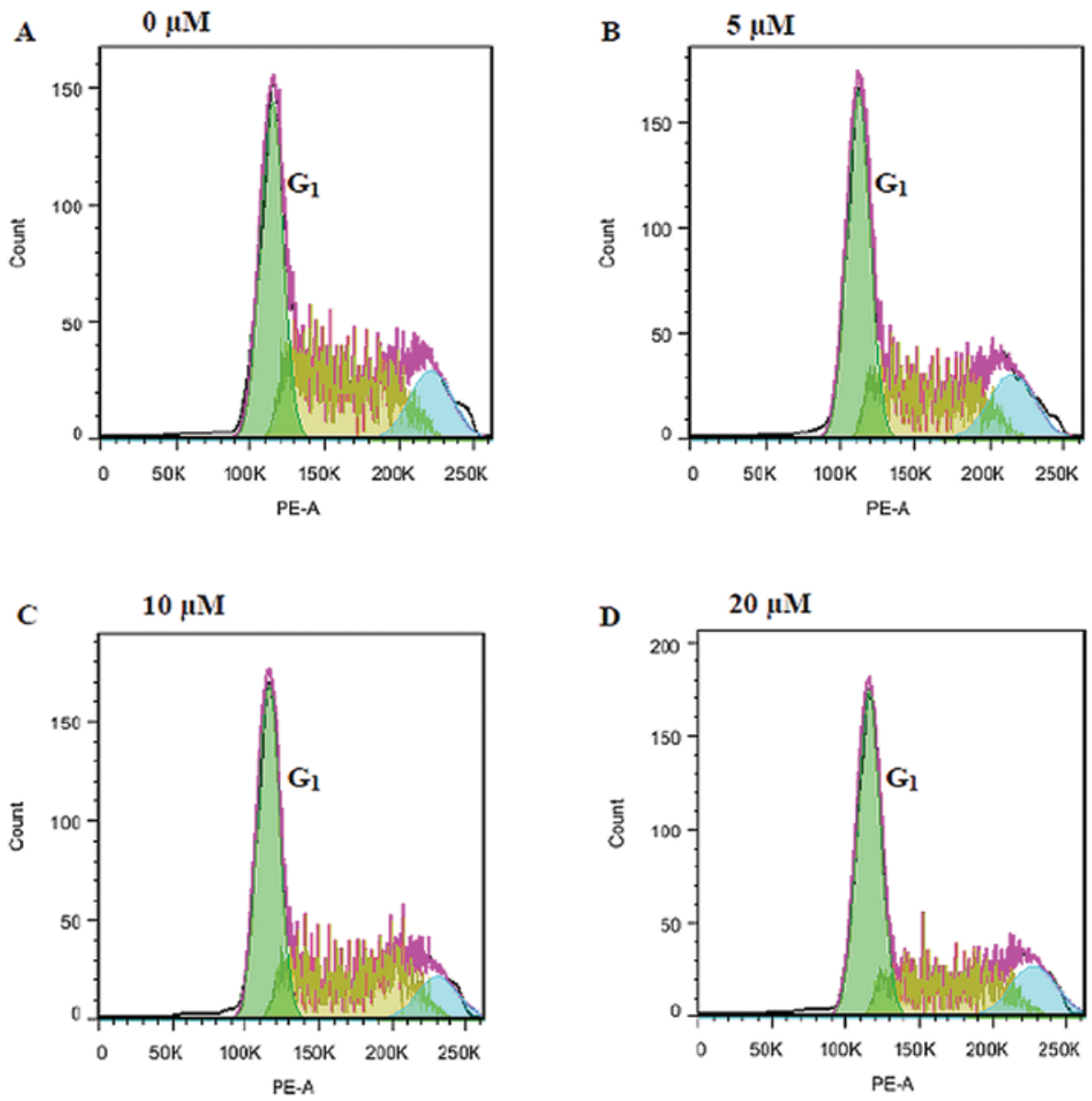

Figure 9. Cell cycle distribution of Huh-7 cells following treatment with berberine for $24 \mathrm{~h}$ : (A) 0 , (B) 5 , (C) 10 and (D) $20 \mu \mathrm{M}$ berberine. The data represent three individual experiments. The results suggest that berberine induces G1/S cell cycle arrest in Huh7 cells after $24 \mathrm{~h}$ of incubation with berberine.
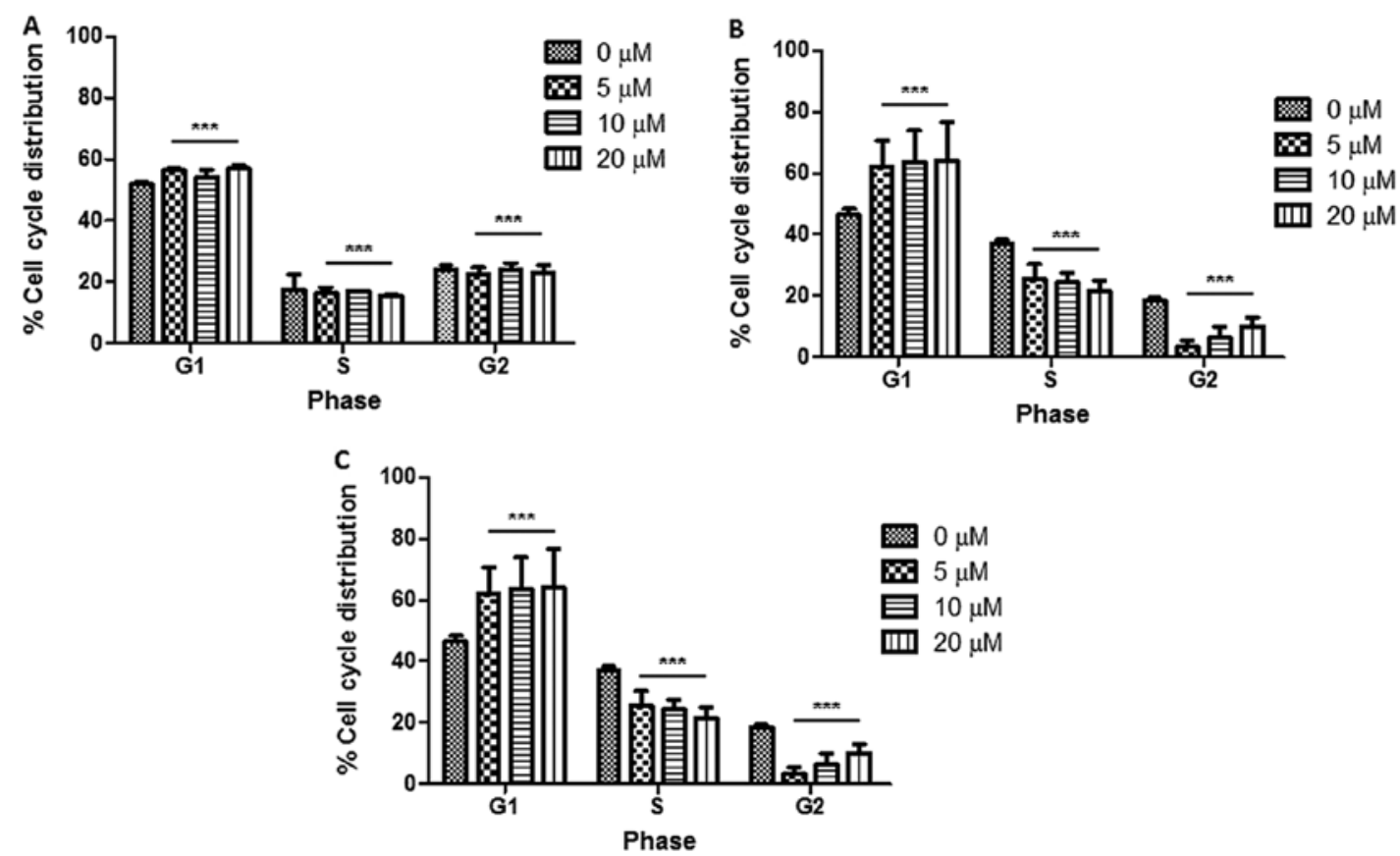

Figure 10. Cell cycle distribution (\%) of Huh7 cells after treatment with berberine for (A) 24, (B) 48 and (C) $72 \mathrm{~h}$.

effect on normal liver cells. The results suggest that berberine exhibited differential effects on normal and cancer cells. The difference in inhibitory activities suggests that berberine initiates a different signaling process in normal and cancer cells. 
FITC Annexin V and PI co-staining revealed that berberine caused apoptosis in Huh7 HCC cells (Fig. 3). The Cide family is known as the inhibitory subunits of endonucleases, cleavage of which is induced by downstream caspases (9). The results support the notion that berberine induced the apoptosis of cancer cells. Fig. 5 shows that Bax, Bid, CIDEA, HRK and p21 were upregulated, while AKT and Bcl-2 were downregulated in Huh7 cells following treatment with berberine. The change in the gene expression profile suggests that berberine induced the apoptosis of Huh7 cells through their intrinsic pro-apoptotic activity which was reported to be associated with mitochondrial dysfunction in cell death (9). The p21 protein is known to serve as a regulator of cell cycle progression at the G1 phase (10). The increase in p21 gene expression (Fig. 6) suggests that p21 regulated the cell cycle progression following treatment with berberine. The AKT protein was reported to participate in the regulation of tumor cell survival and proliferation by stabilizing p21 protein (11). Bcl-2 gene expression was decreased in the present study. The results suggest that berberine inhibited the gene expression of the Bcl-2 gene in the HCC cells. An increased gene expression of Bid implies an increased protein expression of Bid in the cytosol. It was reported that survivin is an anti-apoptosis gene expressed in cancer and lymphoma $(12,13)$. The present results indicate that survivin negatively regulated apoptosis by inhibiting caspase activation. The findings demonstrated that berberine may inhibit survivin gene expression in Huh7 cells. The real-time PCR results agreed with the PCR array analysis regarding the HRK gene, which was reported to be inhibited by Bcl-2 and Bcl-xL (13). Previous studies have reported that increased $\mathrm{Bcl}-2$ protein expression causes resistance to chemotherapeutic drugs and radiation therapy, while decreasing $\mathrm{Bcl}-2$ expression promotes apoptosis induced by anticancer drugs (10). The results reflect the fact that an overexpression of $\mathrm{Bcl}-2$ may cause accumulation of cells in the G0 phase of the cell cycle distribution, resulting in chemoresistance (14). The present findings provide experimental evidence that berberine modulated the protein expression of Bcl-2 associated with caspase-3/7 activities in HCC cells. Higher caspase-3/7 activities were observed in Huh7 cells. It has been reported that cytochrome $c$ interacts with Apaf-1, which activates caspase-9 (15). The effector caspases, caspase-7 and caspase-3, are downstream targets of caspase-9. Poly(ADP-ribose) polymerase (PARP) is a well-known downstream target of active caspase-3 (16). PARP was reported to produce poly(ADP-ribosyl)ation of nuclear proteins with NAD as a substrate. PARP is inactivated by cleavage. The present findings demonstrated that the protein expression of full-length PARP decreased while the cleaved form increased. Since berberine decreased the protein expression of procaspase- 9 and its downstream effector caspases, procaspase -3 and procaspase- 7 , it is possible that berberine cleaves caspase-9, caspase- 3 and caspase-7. Cleaved caspases become active executioners of the intrinsic apoptotic pathway. The protein expression of proliferating cell nuclear antigen (PCNA) was found to be downregulated by berberine in Huh7 cells. The experimental results indicate that as the expression of PCNA was reduced by berberine, fewer cells were able to repair damaged DNA.
The results suggest that berberine may halt HCC cells from dividing, thereby prohibiting deregulated cell proliferation and demonstrate that berberine inhibits the growth of HCC cells by inducing the intrinsic apoptotic pathway, and by arresting the cell cycle at the G1/S phase. Berberine induces apoptotic events in HCC cells through procaspase-9, and its effector caspases, procaspase-3 and procaspase-7. Our findings revealed that berberine possesses potent anticancer activity in human hepatocellular carcinoma.

\section{Acknowledgements}

This study was supported by Tissue Mgfy Ltd. through grant no. 6903292 .

\section{References}

1. Jemal A, Siegel R, Xu J and Ward E: Cancer statistics, 2010. CA Cancer J Clin 60: 277-300, 2010.

2. Perz JF, Armstrong GL, Farrington LA, Hutin YJ and Bell BP: The contributions of hepatitis $B$ virus and hepatitis $C$ virus infections to cirrhosis and primary liver cancer worldwide. J Hepatol 45: 529-538, 2006.

3. Campo RA, Rowland JH, Irwin ML, Nathan PC, Gritz ER and Kinney AY: Cancer prevention after cancer: changing the paradigm - a report from the American Society of Preventive Oncology. Cancer Epidemiol Biomarkers Prev 20: 2317-2324, 2011.

4. Parkin DM: The global health burden of infection-associated cancers in the year 2002. Int J Cancer 118: 3030-3044, 2006.

5. El-Serag HB: Epidemiology of hepatocellular carcinoma in USA. Hepatol Res 37 (Suppl 2): S88-S94, 2007.

6. Mahata S, Bharti AC, Shukla S, Tyagi A, Husain SA and Das BC: Berberine modulates AP-1 activity to suppress HPV transcription and downstream signaling to induce growth arrest and apoptosis in cervical cancer cells. Mol Cancer 10: 39, 2011.

7. Luo Y, Hao Y, Shi TP, Deng WW and Li N: Berberine inhibits cyclin D1 expression via suppressed binding of AP-1 transcription factors to CCND1 AP-1 motif. Acta Pharmacol Sin 29: 628-633, 2008.

8. Wu HL, Hsu CY, Liu WH and Yung BY: Berberine-induced apoptosis of human leukemia HL-60 cells is associated with down-regulation of nucleophosmin/B23 and telomerase activity. Int J Cancer 81: 923-929, 1999.

9. Ghobrial IM, Witzig TE and Adjei AA: Targeting apoptosis pathways in cancer therapy. CA Cancer J Clin 55: 178-194, 2005.

10. Luo Y, Hurwitz J and Massagué J: Cell-cycle inhibition by independent CDK and PCNA binding domains in p21Cip1. Nature 375: 159-161, 1995 .

11. Li Y, Dowbenko D and Lasky LA: AKT/PKB phosphorylation of $\mathrm{p} 21^{\mathrm{Cip} / \mathrm{WAF} 1}$ enhances protein stability of $\mathrm{p} 21^{\mathrm{Cip} / \mathrm{WAF} 1}$ and promotes cell survival. J Biol Chem 277: 11352-11361, 2002.

12. Ambrosini G, Adida C and Altieri DC: A novel anti-apoptosis gene, survivin, expressed in cancer and lymphoma. Nat Med 3: 917-921, 1997.

13. Inohara N, Ding L, Chen S and Núñez G. harakiri, a novel regulator of cell death, encodes a protein that activates apoptosis and interacts selectively with survival-promoting proteins Bcl-2 and Bcl-X(L). EMBO J 16: 1686-1694, 1997.

14. Reed JC: Bcl-2 family proteins: regulators of apoptosis and chemoresistance in hematologic malignancies. Semin Hematol 34: 9-19, 1997.

15. Earnshaw WC, Martins LM and Kaufmann SH: Mammalian caspases: structure, activation, substrates, and functions during apoptosis. Ann Rev Biochem 68: 383-424, 1999.

16. Boulares AH, Yakovlev AG, Ivanova V, Stoica BA, Wang G, Iyer S and Smulson M: Role of poly(ADP-ribose) polymerase (PARP) cleavage in apoptosis. Caspase 3-resistant PARP mutant increases rates of apoptosis in transfected cells. J Biol Chem 274: 22932-22940, 1999. 